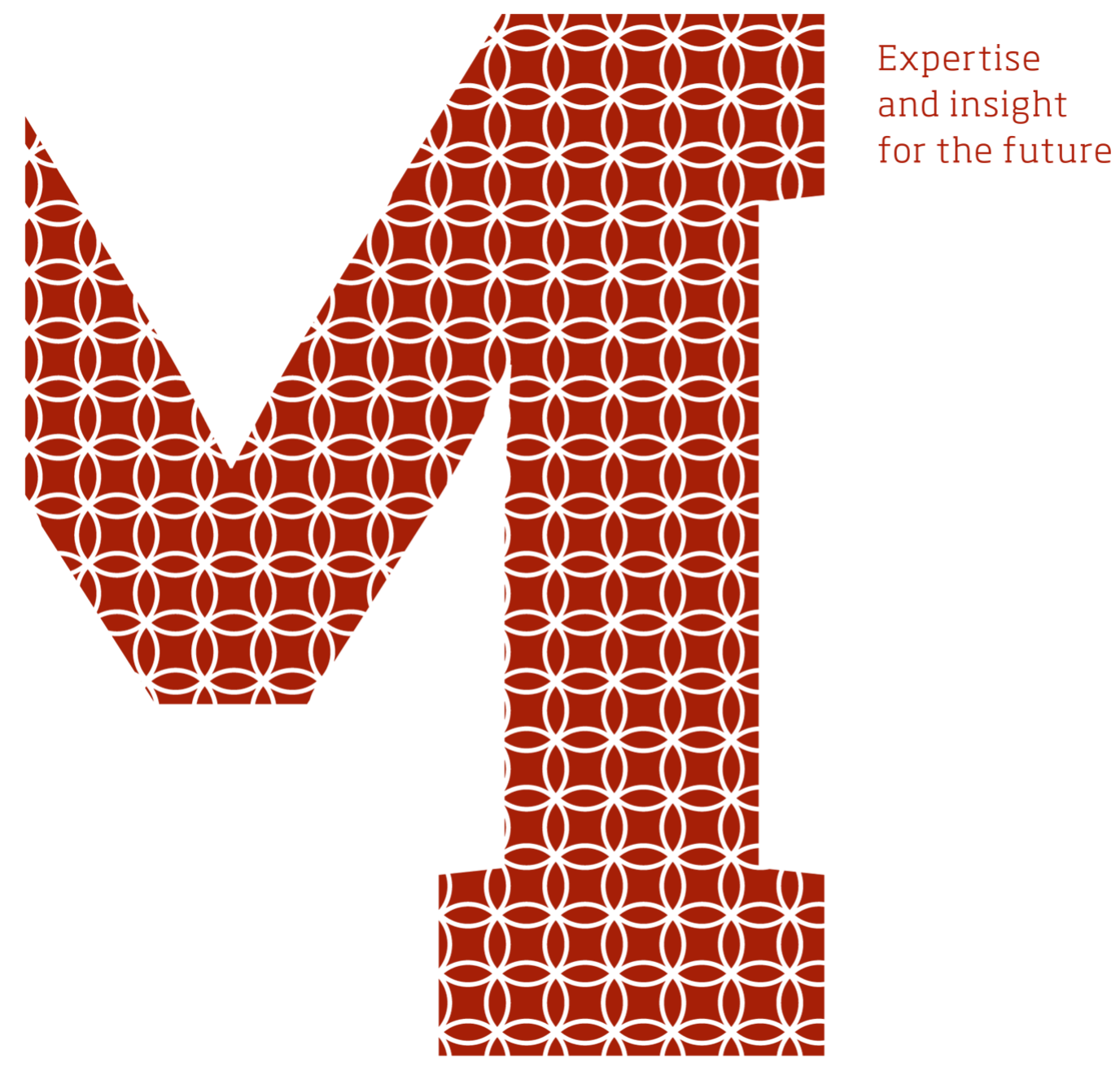

Nina Ylikantola

\title{
Sexual Harassment in Organizations
}

Metropolia University of Applied Sciences

Bachelor of Business Administration

European Business Administration

Bachelor's Thesis

28.4.2021 


\begin{tabular}{|c|c|}
\hline $\begin{array}{l}\text { Author } \\
\text { Title } \\
\text { Number of Pages } \\
\text { Date }\end{array}$ & $\begin{array}{l}\text { Nina Ylikantola } \\
\text { Sexual Harassment in Organizations } \\
37 \text { pages } \\
28 \text { April } 2021\end{array}$ \\
\hline Degree & Bachelor of Business Administration \\
\hline Degree Programme & European Business Administration \\
\hline Instructor/Tutor & Michael Keaney, Senior Lecturer \\
\hline \multicolumn{2}{|c|}{$\begin{array}{l}\text { This Bachelor's Thesis looks into sexual harassment in organizations, how it affects them } \\
\text { and how it can be prevented. This research is based on already published data with a goa } \\
\text { to find out how sexual harassment affects organizations and their employees. } \\
\text { Understanding what sexual harassment is and how it can be seen in the workplace make } \\
\text { it easier to create a better workplace for everyone. } \\
\text { The theoretical part will introduce four models; biological, organizational, sociocultural ano } \\
\text { sex-role spillover, that try to explain what sexual harassment is and why it happens in } \\
\text { organizations. Then the focus will move to the people who are targets of this kind of } \\
\text { behaviour and who are the harassers. } \\
\text { The last part will introduce three different intervention models to how organizations can } \\
\text { prevent sexual harassment from happening or preventing the long-term effects. } \\
\text { Organizations have the option to intervene in sexually harassing behaviour and make it } \\
\text { stop before it can escalate to life-threatening. }\end{array}$} \\
\hline
\end{tabular}




\section{Contents}

1 Introduction 1

1.1 Definition 1

2 History 2

2.1 Anita Hill 3

2.2 \#MeToo 4

2.3 Terminology 4

2.3.1 Sexism 4

2.3.2 Sex Discrimination 5

2.3.3 Subtle Sexual Harassment 5

2.3.4 Gender Harassment 5

3 Why sexual harassment happens in organizations 6

3.1 Models to Explain Sexual Harassment 8

3.1.1 Biological model 9

$\begin{array}{lll}3.1 .2 & \text { Organizational Model } & 9\end{array}$

3.1.3 Sociocultural Models 9

$\begin{array}{ll}3.1 .4 & \text { Sex-role spillover model } \\ \end{array}$

3.2 Gender Experiences 11

3.3 Who Are Targets? 11

3.4 Who Are Harassers? 12

4 Consequences of Sexual Harassment 14

4.1 Organizational Consequences 14

$\begin{array}{lll}4.2 & \text { Psychological Consequences } & 16\end{array}$

$\begin{array}{lll}4.3 & \text { Health-Related Consequences } & 17\end{array}$

5 Real-Life Cases 18

$\begin{array}{llr}5.1 & \text { Boeing } & 18\end{array}$

$\begin{array}{lll}5.2 & \text { McDonald's } & 19\end{array}$

6 How to Prevent Sexual Harassment 21

$\begin{array}{lll}6.1 & \text { Intervention Models } & 21\end{array}$ 
$\begin{array}{ll}\text { 6.1.1 Primary Intervention } & 21\end{array}$

6.1.1.1 Training 24

6.1.2 Secondary Intervention 29

6.1.3 Tertiary Intervention 30

6.2 \#WhylDidntReport 31

7 Conclusion 32

$\begin{array}{ll}\text { References } & 34\end{array}$ 


\section{Introduction}

This thesis examines sexual harassment in the workplace, how sexual harassment affects an organization and how it can be prevented. The research introduces sexual harassment from European and North American points of view since most prior studies have been conducted in these regions. The first part of this research introduces the definition of sexual harassment and its history up to recent years. The second part discusses how sexual harassment affects organizations and in what type of environment it occurs. The third part introduces the consequences of sexual harassment and the last part discusses how organizations can prevent it.

The focus of this research will mostly be on women who experience sexual harassment since the majority of sexual harassment claims are made by women against men. This paper recognizes that men are able to and do experience sexual harassment at workplaces. This doesn't deny or deduct the fact that LGBTQAI+ and women of colour experience additional issues and sometimes deadly harassment.

\subsection{Definition}

Sexual harassment $(\mathrm{SH})$ doesn't have a universally accepted definition (Chamberlain, Crowley, Tope \& Hodson, 2008) but it is usually defined as unwanted sexual behaviours which include verbal and non-verbal behaviour that the recipient experiences as threatening or offensive. Willness, Steel, and Lee (2007) explain that sexual harassment can be defined in terms of psychological and legal definitions. Legal definitions would be quid pro quo and hostile working environment. Psychological definitions would be unwanted sex-related behaviour that the target sees as offensive, exceeding their resources and behaviour that is threatening their well-being. Quid pro quo harassment appears when people with authority misuse power over their employees' job. For example, the boss requires sexual favours and threatens to give the employee a bad performance review or fire them if they don't comply. It also works the other way round: the boss offers the employee a raise, promotion, or other benefits in return for sexual favours (Winer, Burritt and Tillis LLP, n.d.).

A hostile work environment occurs when sexual harassment comes from a colleague or another person who doesn't have power over one's employment. One disrespectful 
sexual comment or gesture does not usually give a base for a legal claim. Hostile work environments are formed by one or two of the following: repeated and common behaviour that makes the environment excruciating or overly offensive and serious behaviour that makes the work environment hostile or dangerous. Once the behaviour grows and the employee believes a hostile work environment exists then they should speak with an attorney. An attorney will help them to report it to the employer and the employer has an opportunity to end the behaviour. If the employer fails to stop the harassment, then the employee has the right to take legal actions (Winer, Burritt and Tillis LLP, n.d.).

In 2006 the European Union defined sexual harassment as following: "where any form of unwanted verbal, non-verbal or physical conduct of a sexual nature occurs, with the purpose or effect of violating the dignity of a person, in particular when creating an intimidating, hostile, degrading, humiliating or offensive environment". U.S. Equal Employment Opportunity Commission (n.d., edited 2002) has defined sexual harassment in their guidelines as following: "Unwelcome sexual advances, requests for sexual favors, and other verbal or physical conduct of a sexual nature constitutes sexual harassment when submission to or rejection of this conduct explicitly or implicitly affects an individual's employment, unreasonably interferes with an individual's work performance or creates an intimidating, hostile or offensive work environment."

\section{History}

To understand sexual harassment, it is necessary to understand the roots of the problem. In law sexual harassment is classified as a form of sex (gender) discrimination because sexual harassment against women falls under gender discrimination. It is essential to understand the underlying reason for gender discrimination. Throughout history, it can be seen that in the early centuries women were considered to be their husbands' property and treated as valued objects. In the United States, women gained voting right in 1920 after decades of fighting for it (Baum, 2019).

Even in the 1950s women were not allowed to open or have their own bank account with their own name without their husband co-signing it. Women were required to have their husbands' signature even if they were earning their own incomes. In 1974 in the US the Equal Credit Opportunity Act was passed, ending the practice whereby banks required 
widowed, divorced, and single women to have a man to co-sign on any applications regardless of the woman's incomes. If a woman wanted to get a loan for a house or a business, she was required to have her husband on the loan (Baum, 2019).

Throughout the decades, women's contributions and discoveries in various industries were overshadowed by gender-biased criticism and attitudinal barriers. Women made major contributions that were often not known by the public and not taught in history classes. Women artists usually used male pseudonyms to get their work published or to be able to make art in a different genre that male critics didn't see appropriate coming from a woman. Also, women encountered harassment and gender-based discrimination in sports (Baum, 2019).

When sexual harassment became publicly recognised as a social issue, many appeared to believe sexual harassment was a behaviour conducted by individuals who suffered from psychological problems. On the other hand, it was suggested that men from certain "classes" only harass; usually, blue-collar, uneducated people who could be anticipated to be "uncouth" or "rough" (Fitzgerald \& Cortina, 2018).

\subsection{Anita Hill}

In North America, the term "sexual harassment" became known in the mid-1970s (Hunt, Davidson, Fielden \& Hoel, 2010), and known in households in 1991 when law professor Anita Hill testified on the Clarence Thomas nomination to the Supreme Court in the US. Hill testified that at the time when she was working as Clarence Thomas' assistant, he had asked her out, talked about pornography with her and had other sexually charged discussions at work (Perez, 2019).

Shortly after Professor Hill's testimony, she started to receive hundreds of letters from people who shared their own stories with her about sexual harassment and other issues they have encountered (Hill, 2011). Many women who had experienced similar behaviour to Anita Hill, wished that having awareness on this issue would make the public, organizations and all industries take sexual harassment more seriously and take preventative measures and focus on it. Due to the testimony, the sexual harassment complaints were increased which was the most notable change. Other changes were that organizations created policies forbidding harassment at workplaces; organizations 
started to have sexual harassment prevention training, and women started to feel more comfortable speaking up about their experiences. However, it soon became clear that the changes were rather cosmetic than systemic. Over the next 25 years, (Perez, 2019) organizations tried to prevent sexual harassment claims by relying on these cosmetic instruments. By focusing on their facade, organizations missed the larger picture - the significance of building a culture of inclusion and respect, not just having policies that say, "no harassment" (Perez, 2019).

\section{$2.2 \quad$ \#MeToo}

In 2006 a movement called 'me too.' was founded by activist and survivor Tarana Burke. The point of the movement is to offer support and bring resources to women who had experienced sexual violence (me too, n.d.). In October 2017, the \#MeToo went viral when actress Alyssa Milano used the phrase and encouraged victims of sexual harassment and sexual assault to tweet 'Me Too' on social media platform called Twitter. The hashtag went viral in the first 24 hours and was tweeted almost half a million times with individual stories that gave a picture of the scale and scope of the issue of sexual harassment and sexual assault (Fortado, 2018). \#MeToo movement empowered women to come forward with their experiences of sexual harassment at workplaces by giving them a platform where they are heard (Baum, 2019). The \#MeToo movement has helped people to find support and companionship via social media, even for the people who are isolated in their workplaces (Stockdale, Bell, Crosby \& Berdahl, 2020). \#MeToo is the opposite of decades of silencing the people who had experienced sexual harassment due to settlement agreements that prohibited people from speaking about their experiences. These agreements have created a barrier that has made preventing sexual harassment difficult and allowed sexual harassment to increase in the workplace (Baum, 2019).

\subsection{Terminology}

\subsubsection{Sexism}

Sexism is an attitude where a person believes that their gender is superior when compared to the other gender (UN Women, n.d.). 


\subsubsection{Sex Discrimination}

Sex discrimination is an extensive term that includes all disadvantageous behaviour in the workplace based on gender, such as paying women less, not hiring them or not giving promotion, assigning them worse work assignments, etc. (Karami, Swan, White \& Ford, 2018). Sexual harassment falls under the term sex discrimination (Stockdale, Bell, Crosby \& Berdahl, 2020), whereas some discriminatory behaviours at the workplace can be sex discrimination but do not qualify as sexual harassment. For example, not inviting women to work trips or to essential meetings where men have been invited (Karami, Swan, White \& Ford, 2018).

It is a behaviour that occurs when decisions related to one's employment are based on their sex or when they are being treated differently because of their gender. For example, every time there are heavy boxes to lift, a woman supervisor asks the men employees to do it. Or every time there are office parties to plan, the man supervisor asks the women employees to plan them (UN Women, n.d.).

\subsubsection{Subtle Sexual Harassment}

Subtle sexual harassment is unwelcome behaviour that has a sexual nature, for example, unwanted sexual jokes, comments, and innuendoes. This behaviour is not a legal term but if it's allowed to go on, it could create a hostile work environment or/and quid pro quo for the recipient (UN Women, n.d.).

\subsubsection{Gender Harassment}

Gender harassment applies to a wide selection of nonverbal and verbal behaviours that aren't targeted at sexual cooperation (Leskinen \& Cortina, 2010). Its goal is not to accomplish sexual cooperation, but instead expresses degrading, insulting, disrespectful or misogynistic attitudes about women; its core is hostility and contempt, causing some people to classify it as gender hostility (Avina \& O'Donohue 2002; Fitzgerald \& Cortina 2018). Common gender harassment, a sub-class that can sometimes be labelled as sexist hostility, contains "woman-bashing" jokes, sexual unattractiveness or the irrelevance of older women, comments regarding that women shouldn't be working in certain jobs and insults about women qualifications. Obviously hostile and clearly sexual are both more harmful shapes of gender harassment (sexual hostility, pornographic 
pictures, referring to women by humiliating names for body parts, brutal remarks about women sexual activity or sexuality). One woman doesn't need to be the target of this type of behaviour; this sexualized version of gender harassment may include gratuitous sexualization of a whole workplace (e.g., sexually offensive posters, cartoons, graffiti, screensavers) (Fitzgerald \& Cortina 2018).

Research has identified new expressions of gender harassment and the first one is gender policing. Gender policing expresses hatred towards women who violate the typical stereotype of femininity. For example, despising those who don't look or behave "womanly" enough or who show interests in things that are traditionally masculine. Gender-policing is more about sex stereotyping than sexual harassment but it can escalate into sexual harassment. Another expression of gender harassment is family/work policing, which controls boundaries between home (a place where women belong particularly when they have children) and work (a place where women are unwelcome and unsuitable). Hatred towards women who combine family and work is a widespread fact, for example, women who have children not being reliable employees or comments that women's right place is at home (Fitzgerald \& Cortina 2018).

Studies constantly demonstrate that gender harassment, whether combined with other types of behaviours or alone, is the most popular form of sexual harassment. Gender harassment confirms that sexual harassment is essentially about the gendered arrangement of power, not desire or romance (Fitzgerald \& Cortina 2018).

\section{Why sexual harassment happens in organizations}

Organizational tolerance is the most powerful aspect when determining if sexual harassment will take place and will it be harmful when it happens (Perez, 2019). Research has shown that employees' perception of organizational tolerance to sexual harassment and how they response to it are related to the frequency of sexual harassment and effectiveness in fighting against it (McDonald, 2012). Research has indicated that stern management norms and an atmosphere that doesn't endure offensive behaviour can prevent sexual harassment even by those who have a propensity to harass. This doesn't mean that personal deviance wouldn't play a role or that some people may not be immune to either consequences or education (Fitzgerald \& Cortina 2018). If organizations are serious about stopping harassment, then they 
should change the organization mindset from complicity and compliance to empathy and bravery (Perez, 2019).

The second possible predictor of sexual harassment is if men outnumber women in organizations, especially leadership positions or men are the only ones occupying the top positions of an organization (Perez, 2019). Studies show that organizations that have larger power differentials between organizational levels have more sexual harassment cases. Other studies show that women experience it more frequently in male-dominated workplaces and occupations than in organizations that are female-dominated or where women are in balance (McDonald, 2012). Not having many women in leadership positions will result in sexual harassment claims to be viewed from one perspective only. Men and women view harassment allegations differently. One gender doesn't view the issue better or worse, they just view them differently (Perez, 2019).

Perez (2019) mentions a survey conducted by Emtrain with In the House that researched sexual harassment happening in the workplace. One of the important observations was to see how genders split when it comes to recognizing offensive or harassing behaviour, and whether resisting unwelcome behaviour affects women negatively or not. The gender split was noticeably presented in a result that compared external and internal data: 6 in 10 male respondents (Perez, 2019) in the In the House/Emtrain survey said sexual harassment never or rarely happens in their organizations. In 2018 Pew Research Center conducted a study to find out that 6 in 10 women (Perez, 2019) say they have experienced sexual harassment in their organization. These statistics were expressed in the comments of the survey. The remarkable difference between the observation of the generality of behaviour that could be addressed as harassing was emphasized in two comments. Male respondent had said that the organization's male owner would at times have consensual sexual relationships with women employees who worked for him. $\mathrm{He}$ continued saying that women didn't protest or object to these relationships, and there were no open threats to what would happen if the women declined sexual advances. Another comment was from a female respondent who said that women are afraid to reject men because they are unsure if it will impact their job (Perez, 2019).

Research has shown that people with hostile sexist beliefs are less likely to find harassing behaviour unwelcome. When presenting stories of sexual assaults at a workplace people with hostile sexist beliefs were less likely to find signs of sexual harassment. When people are more tolerant of $\mathrm{SH}$, they are less likely to see signs of it 
and might not view it as harmful to the person who has experienced it. Women and men who tolerate sexual harassment are also less likely to call sexual assault rape (LeMaire, Oswald \& Russell, 2016).

Willness, Steel and Lee (2007) mention that sexual harassment happens in workplaces that have general mistreatment and the targets have experienced it in other ways. Another mistreatment that can be experienced is known under different names: emotional abuse, incivility, generalized workplace abuse and bullying. These mistreatments refer to actions such as disrespect, verbal aggression, and isolation (Lim \& Cortina, 2005). Lim and Cortina (2005) researched to find out that women who had experienced sexual harassment had also experienced general incivility but women who had experienced general incivility didn't always experience sexual harassment. It shows that sexual harassment often takes place in a workplace that has general disrespect.

Willness, Steel and Lee (2007) also claim that three aspects affect the organizational climate where sexual harassment is happening and those are perceived risk to the victim for complaining, their complaints won't be taken seriously, and a lack of punishments against offenders. The data frequently displays that workplaces can reduce and prevent harassment if they decide to do so (Fitzgerald \& Cortina 2018).

\subsection{Models to Explain Sexual Harassment}

Dekker and Barling (1998) suggest several models in their research on why sexual harassment happens in organizations. The models are the organizational model, the sociocultural model, the biological model, and the sex-role spillover model. McDonald (2012) covers three models in her research: the biological model, a sociocultural model, and a power model. McLaughlin, Uggen and Blackstone (2012) also use the power model suggesting that women who are threatening men's dominance become more frequent targets of sexual harassment. Another research has found support for the paradoxical power-threat model which means that women who are in authority positions experience most likely harassment and discriminations (McLaughlin, Uggen \& Blackstone, 2012). 


\subsubsection{Biological model}

The biological model suggests that sexual harassment isn't harassment and doesn't have harmful consequences, isn't discriminatory or isn't sexist. The model believes that behaviour labelled as 'sexual harassment' is an indicator of the natural attraction between women and men. The model presumes that men behave sexually aggressive in the workplace because they have a stronger sex drive than women do. They don't have any intentions to harass anyone they pursue, and some behaviours may be experienced as unwanted but that is the consequence of their sexual aggressiveness (O'Hare \& O'Donohue, 1998). If this model were true, the targets wouldn't experience negative consequences, and no one would want to make a complaint about it. If sexual harassment is a result of a few 'sick' men, then the harassment complaints should be low and sexual harassment behaviour should be aimlessly scattered across men of all ages, occupational positions, and statuses without a pattern (O'Donohue, Downs \& Yeater, 1998). The biological model is dismissed later on by the recent literature because it doesn't explain same-sex harassment or women in higher positions harassing men in lower ones (McDonald, 2012).

\subsubsection{Organizational Model}

The organizational model suspects that sexual harassment is facilitated through power differentials that are created by a hierarchical structure. People who are in a higher position in organizations have the opportunity to misuse their power for their sexual pleasure through the harassment of the people working under them. Sexual harassment allows superiors to control and intimidate their subordinates. Furthermore, to power differentials, other organizational tendencies are seen in this model as adding to the frequency of sexual harassment. These include the ratio of men to women in the workplace, job functions, contact with the opposite sex, occupational norms, the possibility to make a formal complaint and job alternatives (O'Hare \& O'Donohue, 1998).

\subsubsection{Sociocultural Models}

The sociocultural models of sexual harassment discuss the societal context, reflect a feminist point of view, conceptualizing sexual harassment as a result of patriarchal systems that empower men to use sexual power to preserve and defend male dominance (Rospenda, Richman \& Nawyn, 1998; O'Hare \& O’Donohue, 1998). These 
models suggest that sexual harassment is a result of gender socialization methods that maintain and create power spread between women and men at the societal level (Rospenda, Richman \& Nawyn, 1998). Based on these models, men use harassment to maintain their dominance over women both economically and occupationally by intimidating them to quit their job or limiting their professional growth. Men are rewarded for assertive and aggressive behaviour whereas women are taught to be passive, to be sexually attractive, to avoid conflicts and to feel that they are liable for their own victimization. Sexual harassment is suggested to be a form of 'moral exclusion' where men feel an entitlement to their position as a higher power in society. Due to that, they justify their behaviour and neglect all results of their actions towards the weaker groups (O'Hare \& O'Donohue, 1998). Evidence to support sociocultural models rests on the fact that harassers usually are men and their targets are normally women (Rospenda, Richman \& Nawyn, 1998).

\subsubsection{Sex-role spillover model}

The last model is the sex-role spillover model. This model explains sexual harassment as a result of skewed sex ratios (i.e., the workplace has mostly male employees and only a few women) in the workplace (O'Hare \& O'Donohue, 1998; Fitzgerald \& Cortina, 2018). Workplaces that have been characterized with a skewed gender ratio, assignments and job duties that have been masculine throughout history and an organization that tolerates offensive behaviour usually has more issues with sexual harassment (Fitzgerald \& Cortina, 2018). Multiple women working in female-dominated or in male-dominated workplace lowers sexual harassment because there are multiple women. One woman working in a male-dominant workplace makes her stand out because she is the only one. She will be noticed by her sex role and not her work role. In a female-dominated workplace work role and sex-role tend to overlap. Common jobs for women tend to put the focus on the sex-role aspect and as a result of that, the job itself requires parts of the sex role (O'Hare \& O'Donohue, 1998).

Research has found out that women who work in non-traditional jobs experience more sexual harassment and more negative results from it than women who work in traditionally female jobs. This model has aspects from sociocultural and organizational models and because of that, it is more comprehensive. However, this model fails to include other variables from the organizational model than sex ratio and it ignores 
personological variables that are linked to the target and the harasser that might be important factors (O'Hare \& O'Donohue, 1998).

\subsection{Gender Experiences}

Previous research is mostly based on women and how they experience sexual harassment (McDonald, Charlesworth \& Graham, 2015). Men also report sexual harassment experiences, but women usually experience sexually harassing behaviours more threatening and anxiety-provoking than men (Holland \& Cortina, 2013). Research on men experiencing sexual harassment is more difficult because they are less likely to name sexually harassing behaviours as sexual harassment. They are also less likely to make an official complaint because it would attract attention that they are differing from the typical masculine stereotype (McDonald, Charlesworth \& Graham, 2015). Houle et al. (2011) claim that men are less likely to label a certain behaviour as sexual harassment than women are. In the US 16\% (Houle et al. 2011) of sexual harassment charges were filed by men and the rest were filed by women. One reason why men experience less sexual harassment could be that men have more privileged positions than women, which may shield them from sexual harassment in the workplace (Houle et al. 2011). Another reason that Chan, Chow, Lam and Cheung (2008) claim is that men evaluate sexual harassment as flattering or mutually initiated or it doesn't threaten them, or it doesn't threaten them as much it would threaten women.

\subsection{Who Are Targets?}

McDonald (2012) brings up the typical characteristics which the targets have. Most of the targets are women who are separated or divorced or young women, women in nontraditional jobs, lesbian, women with disabilities and women from ethnic minorities. Holland and Cortina (2013) conducted a study to see if women with feminist attitudes experience more sexual harassment than women with more traditional attitudes. They found out that women who participate in feminist activism reported more likely of being targeted with gender harassment and sexual-advance harassment when comparing to non-activist women. They also found out that women who identified as "feminist" reported fewer gender harassment issues than women who didn't recognize themselves as feminist. They explained that feminist activism is a noticeable behaviour, but identifying as a feminist isn't, which means that feminist activism could trigger 
harassment. Women who label themselves as "feminist" may not make it seem so obvious that they are feminists. Women who openly participate in feminist activities may seem like an obvious threat to the current gender hierarchy which allows men to have more power than women (Holland \& Cortina, 2013).

McLaughlin, Uggen and Blackstone, (2012) claim that men can be targets if they behave in feminine ways and women if they challenge their position in the gender system. They claim that sexual harassment might be used as a tool to police people that behave in a way that isn't appropriate for their gender. Research has found support for the paradoxical power-threat model that women who work in authority positions are more likely to face harassment. It is reasoned that these women challenge the presumptive superiority of men. Another reason is that women supervisors are seen as undeserving of their positions and are often isolated. Research shows that men use harassment and discrimination to get women unemployed in masculine occupations. (McLaughlin, Uggen \& Blackstone, 2012). Women who are seen as threats or status seekers to male monopolies might be targets of sexual harassment as an instrumental strategy some men use to claim their dominance and defend their privileges (Chamberlain, Crowley, Tope \& Hodson, 2008).

Fitzgerald and Cortina (2018) believe that women are sexually harassed because they are women, whatever else they might be. When men are being harassed, it's usually because they are observed to be non-traditional, gay, feminized, weak, effeminate, or in other way seen as "not man enough"; in other words, they are getting harassed as notmen, meaning they are harassed as women (Fitzgerald \& Cortina, 2018).

\subsection{Who Are Harassers?}

Dekker and Barling (1998) mention personal predictors that could be that the harasser has low self-esteem and feels threatened by other people and feels the need to dominate other people. Another predictor is organizational, and it focuses on an organization's policies and procedures. Dekker and Barling (1998) ask in their research if the harassers have low self-esteem because they usually need to show their power and control. This means that people with high self-esteem don't feel the need to show their dominance and power. They found support for this hypothesis from findings that abusive husbands usually have lower self-esteem than husbands who don't abuse. 
Perez (2019) mentions three indicators that indicate people who are more likely to harass. The first indicator is that the harasser sees themselves as a person who is so powerful and above the rules essentially becoming untouchable. Many men who have been accused of sexual harassment, particularly the ones in high-profile news, have/had enormous power. For these people, the temptation to show that they have power, and they can use it becomes so strong that they even show their power far outside the board meetings. In many cases, the men displayed in headlines aren't just sexual predators, but they are also known for aggressive behaviour and use intimidation tactics to fulfil their egos (Perez, 2019).

The second indicator is personality traits. Zeiger-Hill et al. (2016) conducted a study to find out if "Dark Triad" (psychopathy, narcissism, and Machiavellianism) traits can be associated with sexual harassment. Their study found out that these traits have a positive association with a proclivity to sexually harass. It has been argued that men with narcissistic traits might prefer consensual sexual activities but are ready to use sexual coercive behaviours if the women they desire deny sexual access. People who have high levels of narcissism and are in authority positions may be more likely to sexually harass their subordinates to show their dominance or because the idea of sex and power are related together for these people as is the case for males who are more likely to participate in behaviour that is sexual harassment (Zeiger-Hill et al., 2016). Obviously, this doesn't mean that high-powered men who present these traits are automatically going to engage in sexually harassing behaviours, but they are red flags (Perez, 2019).

The third indicator is the power imbalance. If the workplace has a power imbalance to the degree a powerful man harasses or manipulates a woman, he frequently uses that power toward women who are employing less powerful positions, frequently mentioning to the women that he holds the power that can make or break them. The important thing to know is that most people harass because they can (Perez, 2019).

Researchers have tried to identify a model of interpersonal characteristics or easily recognizable demographics that portray the typical harasser, but only with limited success. It is true that some people will harass more likely than others. Research recommends that this tendency is mostly based on hostile sexism, attitudes towards sexuality and beliefs about right roles for women and men, but characteristics may not be immediately apparent. Based on research findings, it could be misleading to create an average profile of the person who harasses sexually based upon socio-demographic 
factors. It appears that sexual harassment occurs in all age categories, occupational levels, and social strata (Fitzgerald \& Cortina, 2018).

\section{Consequences of Sexual Harassment}

Willness, Steel and Lee (2007) claim that sexual harassment is one of the damaging barriers women experience regarding their career success and satisfaction. McLaughlin, Uggen and Blackstone (2017) conducted research and their qualitative data suggests that some women quit their job in order to avoid their harasser. Other women quit due to frustration or dissatisfaction with how their employer responded to the harassment. In both cases, the women who had experienced sexual harassment often reported that quitting their job seemed like the only way to get away from the toxic workplace atmosphere (McLaughlin, Uggen \& Blackstone, 2017).

The consequences of sexual harassment can be divided into three categories: jobrelated, psychological, and health-related outcomes (Willness, Steel \& Lee 2007).

\subsection{Organizational Consequences}

Multiple research has shown that sexual harassment affects negatively the work lives of women. Across different industries, researchers have discovered that confrontations with sexual harassment in the workplace predicts a decrease in job satisfaction (Fitzgerald \& Cortina, 2018). Lim and Cortina (2005) claim that there is evidence of productivity decline, impaired concentration and higher turnover among employees who have experienced uncivil encounters at the organization. Uncivil organization experiences were associated with increased job withdrawal, lower job satisfaction and greater psychological distress. Job-related consequences include employee's affective attitudes like turnover intentions, negative attitudes towards the job, lower job satisfaction and organizational commitment, employees' behaviour like work withdrawal and job performance/productivity (Lim \& Cortina, 2005; Willness, Steel \& Lee, 2007). Other consequences of sexual harassment that have been correlated with job-related include increased team conflicts, damaged team relationship, over-performance demands, decreased justice perception and team financial performance and cognitive difficulties (Fitzgerald \& Cortina, 2018). 
Organizational costs are related to recruiting and turnover, development, and training, investigating the harassment complaint and the legal costs from the activity against the organization. There are indirect and less quantifiable costs that include reduced motivation or morale of employees, absenteeism or tardiness, loss of shareholder confidence and damage to external reputation (McDonald, 2012). Another typical result of sexual harassment is organizational withdrawal. Many women who have been harassed, have engaged in some type of work withdrawal, staying in their job but detached from it. Others have quitted their jobs which is the ultimate form of withdrawal. Organizational withdrawal is usually seen as a method to escape an abusive situation. This method is very effective, but it comes with significant costs such as financial, social and professional (Fitzgerald \& Cortina, 2018).

Research shows that sexual harassment doesn't only lower the victim's productivity, but it will affect negatively the productivity of the workgroup (Willness, Steel \& Lee, 2007). There is evidence of psychological stress among women who haven't been targets of sexual harassment, but they are aware of their co-workers experiencing it. It has been argued that an organization that tolerates sexual harassment will most likely be stressful for women who are working there. Women who know of the sexual harassment happening to their co-workers or who witness it may be concerned if they will also experience such treatment (Einarsen, Hoel, Zapf \& Cooper, 2003).

Organizations usually view legal principles as an enemy but when it's viewed correctly, the law offers a beneficial framework that essentially helps to create a methodology to avoid legal liability and to build a healthy organisational culture. In the US organizations are usually protected from legal liability, excluding some exceptions on state law, if they can show evidence that they have taken measures to create a safe workplace where employees feel that they can report their concerns, knowing those will be taken seriously and investigated fairly and fully, and are conducting effective and proactive measures to stop recognized misconducts. It means that picking a big-picture approach isolates organizations from lawsuits. They are not legally responsible if they provide an environment where employees have tools to solve problems before they intensify, are offered numerous ways to bring out their concerns in case they need assistance to solve the problems, have faith in the system to investigate claims of violation and knowing that the organization is dealing with proven cases of violations evenly (Perez, 2019). 
There are significant societal and organizational costs that are related to sexual harassment. For example, between 1992 and 1994, it was estimated that the United States government had paid more than 320 million dollars (Zeigler-Hill, et al., 2016) for costs that were caused by sexual harassment (Zeigler-Hill, et al., 2016).

\subsection{Psychological Consequences}

Many studies have documented that offensive gender-related behaviour has severe emotional consequences. Numerous strict investigations have verified that sexually harassing experiences can result in significant emotional damage, even when the experiences are less intense and serious than those typically demanded to trigger statutory relief (Fitzgerald \& Cortina, 2018).

Multiple studies have linked sexual harassment to real diagnosable psychological disorder (for example, PTSD, major depressive disorder) and to psychological distress (symptoms) (Fitzgerald \& Cortina, 2018). Psychological consequences include stressinducing strains, well-being/life satisfaction and symptoms that are related to PTSD (Willness, Steel \& Lee, 2007). Other psychological problems include anxiety, fear, and depression (Lim \& Cortina, 2005).

Friborg et al. (2017) conducted a study to find out if there is a relation between depressive symptoms and workplace sexual harassment. They found out that employees who experienced sexual harassment from supervisors or co-workers had a higher level of depressive symptoms when comparing to employees who hadn't experienced sexual harassment or employees who were sexually harassed by clients. Magnusson Hanson et al. (2020) conducted a study among Swedish women and men to see if workplace sexual harassment could result in suicide or suicide attempts. They analysed sexual harassment from co-workers or superiors and sexual harassment from others (for example, clients) and found out that when others were sexually harassing, it was more strongly correlated with suicide and suicide attempts than sexual harassment from coworkers and superiors.

Multiple reliable research has concluded that experiencing sexual harassment, at many levels of intensity and frequency even at low, can result in elevations in psychological pain and reductions in psychological well-being, including significant emotional 
disorders. Although not everyone who has been exposed to sexual harassment will develop emotional distress symptoms, which is much more common and seems to be the normative answer (Fitzegerald \& Cortina, 2018). Chan, Chow, Lam and Cheung (2008) claim that people who experience sexual harassment, have similar psychological symptoms to those who have experienced traumatic event because they expect their workplace to be nonviolent and supportive.

Long term results of sexual harassment are rarely measured, partly because following the victims of sexual harassment in a long term is difficult (McDonald, Charlesworth \& Graham, 2015). Houle et al. (2011) suggest that people who experience sexual harassment at the early stages of their career will most likely be targeted again. Experiencing sexual harassment at the early stages of a career may appear later on as symptoms of depression if experiencing it again. Early harassment could add symptoms of depression which in return adds the risk of being harassed again and having symptoms of depression in adulthood (Houle et al., 2011).

The lack of clarity on whether or not sexual harassment can constitute trauma allows various analysis and discrepant conclusions about what type of incidents legally constitute trauma (Avina \& O'Donohue, 2002). Outside the legal definition, trauma researchers are normally more practical. The National Center for PTSD addresses "Post Traumatic Stress symptoms" attracting attention to its substance rather than legal controversies and technical diagnostic. Sexual harassment victims often experience symptoms of PTSD without fulfilling the bodily injury or risk of death criterion (Fitzgerald \& Cortina, 2018). There needs to be some kind of agreement on whether sexual harassment meets this criterion or not, in order to determine legal responsibility, estimate damages, and estimating and treating sexual harassment victims (Avina \& O'Donohue, 2002).

\subsection{Health-Related Consequences}

Lastly, health-related outcomes include nausea, headaches, exhaustion, shortness of breath, sleep problems, weight gain/loss, and psychosomatic symptoms (Willness, Steel \& Lee, 2007; Lim \& Cortina, 2005; Fitzgerald \& Cortina, 2018). Organizations have been using settlement agreements to silence the people who have experienced sexual harassment in order to protect the organization's reputation. Sexual harassment can be 
a traumatic experience and talking about it to someone could help the target to process their feelings. Due to the settlement agreements that haven't been possible to the targets. Research shows that people who are unable or unwilling to open about their traumatic experiences show higher cancer rates, blood pressure, mortality rates after breast cancer diagnosis and physical disease rates overall. It also shows that targets who talked about their experiences experienced less increase in health problems (Pennebaker \& O'Heeron, 1984).

There isn't as much research done to address the relationship between women's physical health and sexual harassment as there is on professional and psychological outcomes. Such consequences are usually indirect and can be seen through mental health (Fitzgerald \& Cortina, 2018).

\section{$5 \quad$ Real-Life Cases}

\section{$5.1 \quad$ Boeing}

In 2005 the CEO of Boeing, Harry Stonecipher, resigned from his position after there was an investigation where they found out that he had a relationship with Debra Peabody who was an executive at Boeing. Boeing said that Mrs Peabody didn't directly report to $\mathrm{Mr}$ Stonecipher, their relationship was consensual and didn't affect the way $\mathrm{Mr}$ Stonecipher handled Boeing's businesses, but it broke their code of conduct. The affair in itself didn't break the code of conduct, but the board believed that the affair violated it about damaging the reputation of Boeing (Isidore, 2005).

Multiple different variables played a part in this decision. Mr Stonecipher was brought from his retirement to repair Boeing's reputation from a previous scandal that happened 15 months earlier than his own. His resignation was a sign that the board didn't tolerate any missteps especially when they were trying to earn back their place at the top in global corporations. One chairman had said that Mr Stonecipher having an affair wasn't the main reason why he had to resign but the circumstances around the relationship. They believed that the facts demonstrated his poor judgement that would have affected his ability to lead the company (Merle, 2005; Isidore, 2005). 
The board was quick to fire Mr Stonecipher; this raised questions if there had been something else behind his resignation (Jones, 2010). Mr Stonecipher and Mrs Peabody's affair was tipped off by an anonymous employee who had seen correspondence between the two (Isidore, 2005). It was possible that there was an email leakage that could have further demonstrated Mr Stonecipher's poor judgement, or Boeing was worried about a possible sexual harassment lawsuit (Jones, 2010).

In Boeing's case, it is difficult to analyse Mr Stonecipher and Mrs Peabody's relationship. It all started when Mr Stonecipher was the CEO and she worked for him, which shows signs of power imbalance because he had the power over her employment. Usually, in cases of workplace affairs and heterosexual relationships, the woman is the one who will be fired or transferred to a new job position (Williams, Giuffre \& Dellinger, 1999). In this case, Mr Stonecipher had to resign but Mrs Peabody was able to keep her position. What makes this case difficult to analyse is the fact that Mrs Peabody resigned shortly after and later the two got married (The Seattle Times, 2016).

Later on, Boeing has been sued for sex discrimination and retaliation in 2010 (EEOC, 2010) and in 2018 they were sued again and found guilty of not preventing harassment, having a hostile work environment and being negligent in its supervision and hiring (Gurchiek, 2018). Based on these lawsuits it can be assumed that they haven't invested in harassment prevention methods or that the board has failed to communicate its values to its employees.

\subsection{McDonald's}

In 2019 McDonald's fired its CEO, Steve Easterbrook, when he had an affair with a colleague that showed poor judgement and violated McDonald's policy. Due to the \#MeToo movement, workplaces have been forced to rewrite the rules of consensual relationships, specifically for the CEOs (Hall, Asgari \& Waters, 2019).

After Mr Easterbrook was fired, Chris Kempczinski became the new CEO and it was important for him to set the tone for everyone and clearly express his expectations early on (Gray \& Edgecliffe-Johnson, 2020). Therefore, when a later investigation found out that Mr Easterbrook had hidden three other sexual affairs with employees (EdgecliffeJohnson \& Gray, 2020), McDonald's decided to sue Mr Easterbrook to reclaim back the 
package which was given him upon his departure. McDonald's decided to take this into court to expose all the embarrassing allegations against Mr Easterbrook rather than settling everything behind closed doors (Gray \& Edgecliffe-Johnson, 2020).

One reason why McDonald's is doing this so publicly could be the criticism they have received from different groups and campaigns saying that they haven't taken sexual harassment prevention seriously. Some of their workers have said that there has been group retaliation after making complaints, forced to leave from the job or their hours have been reduced. The \#MeToo movement added pressure on how organizations should respond to the sexual harassment allegations and McDonald's showing that they don't take these allegations seriously will harm their company's reputation. Mr Kempczinski said that they will take actions against sexual harassment and they also added more staff to their anti-harassment training. By taking these actions they want to convince their employees that they take these issues seriously. They added new channels to try to encourage people to report behaviour that isn't in line with company values (Gray \& Edgecliffe-Johnson, 2020).

McDonald's case demonstrates how attitudes have changed over time. Former CEO Ray Kroc married Joan Smith in 1969 but before that, she was married to a man who was managing one of the McDonald's outpost and she worked at the hamburger stands (Napoli, 2016). The attitudes were different back then and already mentioned in the history section that women were seen as the property of their husbands and they didn't have that many rights. Evidence of that was when Mrs Smith filed divorce for the first time against $\mathrm{Mr} \mathrm{Kroc}$, the reason was him being violent and having an uncontrollable temper. At the time that was reported in a little box somewhere in the newspaper (Moore, n.d.), rather than attracting the kind of attention more typical of recent events.

Mr Easterbrook's case has made it to the bigger news. This is at least partly because nowadays we have social media that provides news and information to everyone everywhere and movements like \#MeToo that give organizations the pressure to act. As mentioned, attitudes change, and Mr Easterbrook had to step down. In his case there is a power imbalance because he is the CEO, and the women work for him, so he has the power over these women employment. It could also indicate misuse of power especially since he has had multiple sexual relationships with his employees. 


\section{How to Prevent Sexual Harassment}

There are multiple ways in which organizations can prevent sexual harassment. For example, creating and maintaining a transparent policy for tackling and preventing sexual harassment; making sure that all employees know about the policy and understand it; treating sexual harassment as a safety and health problem; supervising policy implementation; dealing formally and informally with sexual harassment by adopting a investigations and complaints procedure; and being mindful of how the law applies to employer liability and sexual harassment (Hunt, Davidson, Fielden \& Hoel, 2010).

\subsection{Intervention Models}

\subsubsection{Primary Intervention}

Primary interventions aim to focus on the root cause of the issue, preventing issues from developing. An organization can have precursors or risk factors, for example, high power differentials between men and women and unequal gender ratios. Without any acceptance of preventative measures, risk factors could lead to touching or inappropriate jokes and other low-level harassments. Low-level harassment may escalate to assault, rape or sexual coercion that can be defined as progressive stages of sexual harassment if the organization hasn't implemented successful preventative measures (Hunt, Davidson, Fielden \& Hoel, 2010).

From a preventative management perspective, it is important to implement initiatives and policies before the issues develop, it is also easier to discuss the problems of sexual harassment. At this point, the employees and the organization can together create an unhealthy organization where sexual harassment is ingrained in the workplace culture. Strong organizational culture is important because it can show intolerance towards sexual harassment. An official sexual harassment policy can assist to set behavioural guidelines which may encourage victims of sexual harassment to report the incidents and those may also intimidate potential harassers. Policies alone might not be a sufficient way to deal with sexual harassment effectively (Hunt, Davidson, Fielden \& Hoel, 2010). Managers of the organization must do their part and communicate convincingly and precisely on topics that are sensitive and complex like sexual harassment (Perez, 2019). It is important to communicate and all employees to understand that the organization has zero tolerance for sexual harassment (Hunt, Davidson, Fielden \& Hoel, 2010). 
On the other hand, many organizations have embraced the zero-tolerance of sexual harassment without explaining the different levels such as what type of behaviour is not tolerated and what are the consequences of different violations. Without the explanation, these policies will do more harm than good. It implies that a person who makes one sexual joke should be punished the same as someone who is charged with sexual assault. Overall, having zero tolerance will create confusion and fear for women and men. Men will wonder if they will be fired for complimenting someone or making a joke. Women will think they shouldn't report someone because that person might get fired (Perez, 2019).

Policies that are meant to protect the employees can lead to growing sex segregation and restricting all relationships, even the consensual ones. For organizations it's important to implement policies based on empowerment, show formal support to the employees who have experienced sexual harassment and punish the perpetrators unconditionally (Hunt, Davidson, Fielden \& Hoel, 2010).

It is difficult to develop appropriate policies and implement corrective actions of what constitutes outrageous sexual harassment. Another challenge is to know if there is sexual harassment because there aren't many complaints or are too afraid to come forward. The policies vary, depending on the location, nature and size of the organization and there are not universally popular procedures for implementing sexual harassment policies. Common elements in policies include policy statements, a complaint procedure, monitoring and training, remedial measures, and evaluation (McDonald, 2012).

The person experiencing harassment can file a formal complaint but only between $5 \%$ $30 \%$ (McDonald, 2012) file it and less than 1\% (McDonald, 2012) participate in legal proceedings. Most of the targets don't file any complaints to outside bodies or through internal procedures (McDonald, 2012).

McDonald, Charlesworth and Graham (2015) bring up six features that are emphasized when implementing policies. Firstly, the policies should be based on a clear understanding of what type of behaviour is sexual harassment and what isn't in the organization. In order for all the members of the organization to get support for addressing unethical workplace practices, higher management must understand what behaviour consists of injustice and wrongdoing, and the consequences the organization 
may endure if the harassment continues. The second element of an effective sexual harassment policy is visibility. Organizations should set clear behavioural norms and policies regarding sexual harassment, which should be extensively known, with open and apparent statements that sexual harassment won't be accepted in workplaces. The third feature discusses the way protections and grievance procedures are framed. This can be a complicated issue because 'no tolerance' policies may further prevent sexual harassment, but they might put more focus on an organization's image rather than on what complainants wish. There is a common unanimity that perceived accessibility of unofficial advice and arrangement of numerous communication channels are vital management strategies to increase employees' trust in sexual harassment policies (McDonald, Charlesworth \& Graham 2015).

The fourth feature is based on modelling and efficient senior-level management. It includes sexual harassment and gender equality's point of view formulation and communication of relevant policies and dividing appropriate resources for training and policies. Policy-related management strategies that are meant to prevent other types of organizational wrongdoings have also been brought up. These include building stimulus for correct internal reporting for the prize structure, providing comments and giving credit to project managers for taking action (McDonald, Charlesworth \& Graham 2015).

The fifth feature of efficient policy that is identified in the sexual harassment literature is the incorporation of a statement of purpose to supervise instantly and seriously, and a clear definition of the consequences of violation. The assurance of punishment for sexual harassment might be a more effective way to prevent sexual harassment than the severity of the punishment. There are multiple reasons why sexual harassment is rarely reported, for example, self-doubt, lack of information of rights and fear of losing a job but a major reason is an assumption that there will be no penalty for the harasser (McDonald, Charlesworth \& Graham 2015).

The sixth and last feature is a commitment to wider gender equality goals. For example, putting the focus on relationships between genders is essential, whereby sexual harassment policies are described in gender-specific terms, considering power differentials. In male-dominated workplaces, it is important to provide distinctly expressed opportunities for women to democratically and collectively take part in order to challenge predominant regimes of control and aim for an inclusive work environment (McDonald, Charlesworth \& Graham 2015). 
Even though organizations can have policies that frameworks the reporting process, a simple statement informing how the organization will handle the report and instructing how to report isn't enough to encourage the employees to report sexual harassment to an authority or to stop inappropriate behaviour from happening. People who experience sexual harassment are usually confused about what has happened to them, they are afraid that no one will believe them, others will think badly about them, they may feel guilt and shame, and they frequently don't identify the situations to be as serious enough that it should be reported (Foster \& Fullagar 2018).

Organizations that have explicit sexual harassment policies and embrace a proactive approach usually have fewer issues with sexual harassment. One effective method to prevent sexual harassment can be training which is used at the primary intervention and can contain methods like role-plays, board games, internet-based training, group discussion, video-based training, lectures, and sensitivity training. Training sessions can inform employees of sexual harassment and give them the right skills to process sexual harassment complaints if it ever occurs. Organizations have to base the change process into three steps: recognizing the problem; employee development and learning; and evaluating the effectiveness of changes (Hunt, Davidson, Fielden \& Hoel, 2010).

\subsubsection{Training}

Besides policies, primary prevention also includes training. Training sessions should be organized regularly and generally across all levels of the organizations and not only to specific groups and to people who attend voluntarily (McDonald, Charlesworth \& Graham 2015). For organizations to organize sexual harassment training is expensive and it has been estimated that only the employers in the US have spent over 10 billion dollars (Roehling \& Huang, 2018) yearly on sexual harassment training. If the training is effective, the money was well spent to help the organizations and individuals to avoid any major costs (health-related, psychological and organizational costs) related to sexual harassment. Training effectiveness can be measured to what extent the training has given the wanted results. The outcomes of training that can measure the effectiveness of training are increased motivation, how the people felt afterwards of the session, learning outcomes, its impact on the organization's efficiency, is the return higher than the investment in training and how the skills and knowledge were transferred to the workplace (Roehling \& Huang, 2018). 
The training program shouldn't only provide employees with the legal definition of sexual harassment but also address the support which is provided by the organization for the employees who have experienced sexual harassment. It takes a lot of courage to report sexual harassment so it would be helpful to inform them of available resources which could help the employees through the process of reporting (Foster \& Fullagar 2018). Studies imply that universal sexual harassment training has an effect on the workplace's culture and has a bigger impact in the sense that it leads to further recognition of sexual harassment. It is also recommended that sexual harassment training is included in new employees' orientation to ensure it is addressed and recognized (McDonald, Charlesworth \& Graham 2015).

When designing the content of the training there appear to be four important principles. Firstly, the training should be built and developed around the information collected from organizational evaluations. Evaluating early risk elements includes recognizing situations where sexual harassment will probably occur, appraise women's role, positions, and status in the workplace, and executing anonymous and regular attitude surveys including measures of sexual harassment. Secondly, training should increase awareness and clear up misunderstandings about what form of sexual harassment whilst emphasising and strengthen acceptable behaviour norms. To clear misunderstandings around sexual harassment, studies have emphasised the importance of rehearsal and modelling. In training, the use of rehearsal and modelling is thought to develop resolution-handling skills and sensitivity to behaviours that can be interpreted as sexual harassment (McDonald, Charlesworth \& Graham 2015).

Thirdly, research shows that managers' training should contain conflict management, containing the facilitation techniques and managing of emotions. It is recommended to include emotional and communication skills training to make sure that managers can show empathy, investigate effectively, and listen actively, assisting them to deal with any tendencies to deny the legality or become defensive of complaints (McDonald, Charlesworth \& Graham 2015). It was already mentioned that being embarrassed would stop the people from reporting sexual harassment so the reporting procedure should be as expeditious, confidential, and unencumbered as possible in order to save organizational resources but also protect the privacy of the people who report in order for them to not become embarrassed (Foster \& Fullagar 2018). Managers who have had conflict management training are thought to successfully address the fears of employees, 
who have experienced sexual harassment, about retaliation and to negative outcomes that weren't expected (McDonald, Charlesworth \& Graham 2015).

Fourthly, training should challenge organizational cultures that are based on a specific gender. Meta-analytic and cross-sectional studies show that sexual harassment is more common in occupations that are male-dominated than in female-dominated and genderbalanced workplaces. The organizational sex ratio of the organization isn't the problem that renders sexual harassment; instead, organizational environments that have a hierarchical structure, more specifically organizations that have cultural norms associated with posturing and sexual bravado and where it is punished to denigrate feminine behaviours. That is why training should address cultural issues that are genderrelevant (McDonald, Charlesworth \& Graham 2015).

There have been a few studies about whether the training is effective or not. One study found out that the people who observed the training as effective were older workers and on average men when compared with younger workers and women. People with higher levels of education and who were divorced, also observed the training to be less effective (Hunt, Davidson, Fielden \& Hoel, 2010). Studies declare that even though reactions towards the training were usually positive, there was a small group of people who had powerful negative reactions. But usually, sexual harassment training is seen positively and observed as helpful by people (Roehling \& Huang, 2018).

Studies have investigated training videos and workshops to see if they are effective and found that they can be successful in informing employees of sexual harassment, what type of behaviour is sexually harassing and attempting to fight against it. It seems that approaching sexual harassment training with multiple different methods can be effective to reduce sexual harassment in an organization (Hunt, Davidson, Fielden \& Hoel, 2010). From a legal point of view, training is effective if it fulfils all the minimum legal demands for training provided by the employer, in restricted circumstances and jurisdictions where workplaces are required to have some type of sexual harassment training; the amount of external sexual harassment claims against the employer decreases; it adds employer's possibilities to win these claims if presented; and if the employer loses against these claims, it reduces the employer's responsibility to pay for the damages (Roehling \& Huang, 2018). 
Research has found out that when workplaces had implemented multiple means (e.g., training, complaint procedure, policies) to deal with sexual harassment, women reacted more assertively to complain about sexual harassment. It also showed that procedures and policies affect men's behaviour. Furthermore, the strategies the workplace had adopted depended on the nature of sexual harassment it affected. The research suggests that both proactive and informational methods are valuable in reducing harassment in general and especially environmental patterns of sexual harassment for example, pinups and pornographic posters or disparaging sexual categorical remarks about women. However, personal forms of sexual harassment can't be effectively prevented if the employees have only been provided with information about it. In this perspective, proactive strategies are effective when dealing with sexual harassment (Gruber, 1998). According to Gruber (1998), women were less likely to be victims of obnoxious sexual questions or comments or to be physically threatened in workplaces that had implemented proactive approaches.

Goldberg (2007) conducted a study to see how conflict avoidance and sexual harassment training impact the responses to sexual harassment. The study found out that due to the training, employees avoided conflicts with the harasser and formal reporting. The finding suggests that plaintiffs may experience extra obstacles in an already complicated process due to the training. Organizations might be worried that training will encourage employees to seek external advocacy, but these claims have been found to be false. Organizations offering sexual harassment training doesn't seem to attract more legal procedures, instead, it may encourage everyone to take action as soon as the issues rise which will be beneficial to employees and the workplace. Research also shows that power plays a big part in conflict resolution because people who don't have it usually avoid conflicts when compared with the ones with power. This information isn't surprising since people in power positions are generally the ones who are sexually harassing subordinates (Goldberg, 2007).

However, there isn't confirmed yet that such training will work in the long-term, and the studies have relied on instant reactions to training rather than seeing if it had made a real change in the employees' behaviour or attitudes. Additionally, despite the success of a few training methods in changing attitudes and adding knowledge towards sexual harassment, the bottom-up approach isn't adequate if the goal is to eliminate sexual harassment from organizations. The top-down approach is an important aspect when 
preventing sexual harassment, transferring the message that this type of behaviour is not acceptable and won't be tolerated (Hunt, Davidson, Fielden \& Hoel, 2010).

From my perspective, sexual harassment training can be effective if it's done correctly, and the organization's culture supports it. But if employees see or feel that the management doesn't follow its own guidelines, the employees will get the impression that they don't need to follow them either. In that sense, the training is a waste of money and time because no one sees it beneficial if people won't change their behaviour. On the other hand, organizations might feel the need to provide sexual harassment training even if it's not beneficial because they want to show that they care about these issues. Some organizations might care about these issues when the bigger audience or media is talking about them. Then they will make the "required" changes but after a while, they will ignore the issues again. Of course, there might be organizations that will continuously try to do better even though the bigger audience and media isn't talking about sexual harassment at the moment, but they want to do better for their employees.

Comparing if training costs are cheaper than the lawsuit costs is difficult because the training costs depend on multiple variables. It depends on the number of employees, location, what type of training they are providing and for how long. Lawsuit costs depend on the number of employees who sue, how long it will last, the severity of harassment and how long the harassment has been going on. For example, in 1998 Mitsubishi lost a sexual harassment lawsuit and had to pay 34 million dollars (Los Angeles Times, 1998) to 350 women (Los Angeles Times, 1998). In their case training could have been cheaper than a lawsuit and it could have brought down the number of women who took part in the lawsuit. Another example is a case in 2013 when a lawsuit against Wal-Mart was filed. Wal-Mart was found guilty of sexual harassment, sex discrimination and retaliation. They had to pay 363419 dollars (U.S. Equal Employment Opportunity Commission, 2014) to the victim. After the incident, Wal-Mart provided sexual harassment training at that one specific store to the managers and HR managers who were responsible for that store (U.S. Equal Employment Opportunity Commission, 2014). In my opinion, training would be cheaper in this case too. Wal-Mart has many stores in the US and around the world so training would cost them a lot of money, but it would be cheaper than getting a lawsuit from every store. Also, if they had provided training before the incident, they could have possibly avoided this case. 


\subsubsection{Secondary Intervention}

Secondary interventions refer to immediate response to how organizations respond to sexual harassment when they face it and aim to prevent it to get any further, for example making sure that they are using an effective complaints procedure. In order for organizations to create effective complaints procedure, it's essential to understand how victims respond to sexual harassment and how they cope with behaviours that are sexual harassment and filing complaints. Supported responses are more efficient when dealing with sexual harassment and note, confrontation, negotiation and advocacy searching are ways in which the victim can effectively encounter the issue of sexual harassment, the efficiency of these approaches are depending on multiple circumstances, such as power relations, group/work characteristics and individual characteristics (Hunt, Davidson, Fielden \& Hoel, 2010).

Organizational grievance methods are the most frequent action through which employees' rights will be executed. There are strong proofs to suggest that grievance procedure is often perceived by the employees to be: hostile and adversarial; risky in terms of seclusion or retaliation from colleagues; lacking confidentiality; and likely no one will do anything. Especially men who are less likely to call sexually harassing behaviour sexual harassment, seem to be less eager to participate in official complaint processes because it attracts attention to them that they don't fit into the classical masculine stereotype. Sexual harassment grievance procedures are usually useless because risk management in organizations policies and the dual discourages juridical compliance perform more to protect the organizations from liability than to assist or protect the people who have made the complaint. Another challenge to respond effectively to reports is that sexual harassment often has little evidence, often happening without witnesses and without the straightforward observation of sexual harassment (McDonald, Charlesworth \& Graham 2015).

Attempting to indicate the challenges related to reporting has led to numerous proposals for secondary prevention. These include the availability of different reporting channels, the possibility to use arbitration, making sure that managers respond to the complaints appropriately, the investigations are timeliness and the method of suitable punishments. Powerful complaint-processing requires that the employee who has made the complaint perceives the process as effective and fair even if the outcome isn't what they wished for. When evaluating the effectiveness of grievance procedures, the perceived fairness 
is usually the favoured method, since it is difficult to know from other measures such as arbitrations rates and settlement rates (McDonald, Charlesworth \& Graham 2015).

Weak punishments deflect any of the responsibility of managers and the organizations for discrimination and demonstrate a tolerant climate, suggesting a need to transfer the burden of recognising unprofessional behaviour from the employees to the organization itself. This has been researched in a whistle-blower study of employees who saw wrongdoings but didn't report it because of the thought that there was nothing that could be done in order to correct the situation. Thus, observations of distributive fairness depend on the satisfaction of the result such as there are no retaliation against the whistle-blower or complainant and the wrongdoing has ended (McDonald, Charlesworth \& Graham 2015).

Based on these studies it is evident that the choice of reporting sexual harassment or not is complicated. Additionally, this is intensified when reflecting that in most cases sexual harassment is continuous, rather than a one-time incident. Thus, the victim may feel a variety of various emotions during these events (Hunt, Davidson, Fielden \& Hoel, 2010).

\subsubsection{Tertiary Intervention}

Once sexual harassment has taken place, tertiary interventions have longer-term answers to the problems that have occurred to deal with permanent consequences, prevent new harassment and victims, restore safety and health and minimize harassment's impact. Due to the significant negative health, psychological and jobrelated outcomes that victims experience, tertiary interventions are important to sexual harassment (McDonald, Charlesworth \& Graham 2015). Rehabilitation procedures should make sure that the victims or/and any other people's, whose working lives have been affected by sexual harassment, have been returned to normal as fast and effectively as possible (Hunt, Davidson, Fielden \& Hoel, 2010).

Further clarifying why tertiary interventions are important is that sexual harassment poses long-term consequences for the organizations which were mentioned in the organizational consequences. Lasting victimization of employees who had made a complaint has been proved in grievance-management research. Studies of postsettlement outcomes for employees who hadn't made a complaint compared to the ones 
who had made one indicated that employees who had made a complaint had reduced performance ratings, attendance rates and promotion rates, and in the following year of the complaint, they had higher quit rates (McDonald, Charlesworth \& Graham 2015).

\section{2 \#WhylDidntReport}

In 2018 Dr Christine Blasey Ford testified against Judge Brett Kavanaugh's nomination to the Supreme Court accusing him of assaulting her sexually 36 years ago (TIME, 2018). Dr Blasey Ford has told that the reason why she decided to testify was that she was inspired by Anita Hill's testimony and she felt that testifying was her duty and a right as a citizen. Even though she testified in 2018 she received threats and harassment which led her and her family to move out of their home (Kindelan, 2019). Dr Blasey Ford's testimony attracted a lot of publicity and attracted the attention of, now a former President of the United States, Donald Trump's attention. President Trump decided to tweet saying that if the attack was as serious as Dr Blasey Ford claims, she would have reported it at the time it happened. Social media quickly responded to it with a \#WhylDidntReport where thousands of women were sharing their stories about why they hadn't reported their assaults or harassments (BBC News, 2018).

Research that discusses reporting behaviour has analysed why women decide not to report sexual harassment using frameworks. Firstly, there are approaches like decisionmaking and practical that mainly include fear of revenge. Secondly, multiple research has used psychosocial explanations, which highlight such gender attributes as disgust at confrontation and the priority for caring instead of the need for justice. Foster and Fullagar (2018) conducted a study to research why people don't report sexual harassment and whether people would report sexual harassment in a hostile work environment. The participants of the survey were more promising to report sexual harassment if they perceived that their reputation wouldn't be ruined, the harasser would get punishment and reporting the harassment would make the victim feel good about themselves. They found out that the possibility of being embarrassed is a major reason why people may not report sexual harassment (Foster and Fullagar 2018).

McDonald (2012) claims that the reason why people don't report sexual harassment is fear of losing their job; fear of retaliation or retribution; not wishing to be seen as a victim; fear of being 'too sensitive', self-doubt; the belief that there won't be a penalty for the 
harasser; lack of access to external supports; and not knowing their rights. McDonald (2012) also claims that studies are supporting these factors because people who have reported sexual harassment have sometimes worsened the situation, or it hasn't improved. The targets who didn't file a complaint rather deal with sexual harassment in isolation or with the help of their friends and co-workers. Some employees can leave the organization, continue to tolerate it, or find other ways to deal with it.

\section{Conclusion}

Sexual harassment is still a fairly new research area since it has been a term for less than 50 years. There are still problems when it comes to defining the term and the legal aspect of it. It is important to understand the origins of sexual harassment in order to understand the issue. Sexual harassment can be explained with multiple models that combine different aspects of each other, but no model can fully explain it. There are general definitions but when it comes to the little details and legal definitions then there are some deficiencies. For example, what evidence are valid in court and how it can be proved. It is clear, that there are multiple reasons why someone is being sexually harassed but the most obvious reason is being a woman. The obvious reasons why harassers harass are because they can, and it makes them feel powerful.

Common for all research has been that they agree there are multiple different ways of how sexual harassment will harm an organization, from one employee to a whole organization. The consequences vary from person to person, organization to organization, not everyone who experiences sexual harassment will have emotional distress or physical symptoms. Most symptoms the targets experience come from the fact that they can't talk about it or they feel that they can't talk about it to anyone. Harassment is happening in organizations that are more tolerant towards it or that would rather silence the targets than change the company's policies or the culture. Fortunately, movements like \#MeToo makes it possible for people to talk about these issues and know that they aren't alone with their experiences.

Nowadays it's easier to bring up your own experiences of sexual harassment or sexual assault because our society reacts to these cases differently than it did previously when the victims were silenced. It is more normal to talk about these issues because there isn't as much stigma around these topics anymore. The culture and attitudes have changed 
but also social media makes it easier to talk about. Even though Dr Blasey Ford testified in 2018 when \#MeToo was making headlines the society and bigger audience still didn't respond to her testimony as openly as one could think since she had received threats to her home to the point she had to move out. One reason for the threats could also be that Donald Trump was a president at a time and he had a habit of exaggerating things and saying things without checking the reliability. If he said that he didn't believe Dr Blasey Ford or that her testimony was an attack towards him or Republicans, his supporters would believe it. His supporters would start to believe that this is a political issue where Democrats had paid for her testimony. Dr Blasey Ford shouldn't feel that her traumatic experience is a political weapon for someone to reach their goal and no one should have downplayed her experience because they thought that she was lying.

In the future, the research could focus on the long-term effects of sexual harassment or if the prevention methods work in the longer term. It would be interesting to see if the people who have experienced sexual harassment and have psychological or physical symptoms to see how long they will be experiencing the symptoms. Will they be experiencing them for the rest of their lives, or did they decrease or disappear after they made changes in their lives (e.g., quit their job, talked to a professional, etc.). Prevention methods' effectiveness has been studied in the short-term, but it would be interesting to see if they change people's attitudes and behaviour in the long run. There is less research done on men and how they experience sexual harassment so that is also an aspect that should be researched in the future.

Sexual harassment isn't always black and white because everyone views it differently. Hopefully in the future people will talk more openly about how common sexual harassment is and will offer support to those who have experienced it instead of silencing them. 


\section{References}

Avina, C., O'Donohue, W., (2002) 'Sexual Harassment and PTSD: Is Sexual Harassment Diagnosable Trauma?' Journal of Traumatic Stress, 15(1), 69-75

Baum, B., (2019) 'WORKPLACE SEXUAL HARASSMENT IN THE "ME TOO" ERA: THE UNFORESEEN CONSEQUENCES OF CONFIDENTIAL SETTLEMENT AGREEMENTS' Journal of Business and Behavioral Sciences, 31(1), 4-24

BBC News (2018) '\#WhylDidntReport: The hashtag supporting Christine Blasey Ford' [online] Available at https://www.bbc.com/news/world-us-canada-45621124 (Accessed 26 March 2021)

Berdahl, J.L., Magley, V.J., Waldo, C.R. (1996) 'THE SEXUAL HARASSMENT OF MEN' Psychology of Women Quarterly, 20, 527-547

Braun, S., (1998) 'Mitsubishi to Pay $\$ 34$ Million in Sex Harassment Case' Los Angeles Times [online] Available at https://www.latimes.com/archives/la-xpm-1998-jun-12-mn-59249-story.html (Accessed 28 April 2021)

Chamberlain, L.J., Crowley, M., Tope, D., Hodson, R., (2008) 'Sexual Harassment in Organizational Context' Work and Occupations, 35(3), 262-295,

Chan, D. K-S., Chow, S. Y., Lam, C. B., Cheung, S.F. (2008) 'EXAMINING THE JOB-RELATED, PSYCHOLOGICAL, AND PHYSICAL OUTCOMES OF WORKPLACE SEXUAL HARASSMENT: A META-ANALYTIC REVIEW' Psychology of Women Quarterly, 32, 362-376

Dekker, I., Barling, J., (1998) 'Personal and Organizational Predictors of Workplace Sexual Harassment of Women by Men' Journal of Occupational Health Psychology 3(1). 7-18

Edgecliffe-Johnson, A., Gray, A., (2020) 'McDonald's sues axed chief over sex claims' Financial Times (Europe) 6

Einarsen, S., Hoel, H., Zapf, D., Cooper, C., (2003) Bullying and Emotional Abuse in the Workplace. London: Taylor \& Francis, 91-92

EUR-Lex - 32006L0054 - EN - EUR-Lex [Internet]. Available from: http://eur-lex.europa.eu/legalcontent/EN/TXT/?uri=CELEX\%3A32006L0054 (Accessed 22 January 2021)

Fitzgerald, L.F., Cortina, L.M., (2018) 'Sexual Harassment in Work Organizations: A View From the Twenty-First Century' In J.W. White \& C. Travis (Eds.), Handbook on the Psychology of Women. Washington, DC: American Psychological Association

Fortado, S., (2018) 'Workplace Sexual Abuse, Labor and the \#MeToo Movement' Labor Studies Journal 43(4) 241-244

Foster, P.J., \& Fullagar, C.J., (2018) 'Why Don't We Report Sexual Harassment? An Application of the Theory of Planned Behavior' Basic and Applied Social Psychology, 40(3), 148-160 
Friborg, M.K., Hansen, J.V., Aldrich, P.T., Folker, A.P., Kjær, S., Nielsen, M.B., Rugulies R., Madsen, I.E.H., (2017) 'Workplace sexual harassment and depressive symptoms: a crosssectional multilevel analysis comparing harassment from clients or customers to harassment from other employees amongst 7603 Danish employees from 1041 organizations' BMC Public Health 17(675), 1-12, Available from: DOI 10.1186/s12889-017-4669-x (Accessed 20 January 2021)

Goldberg, C.B., (2007) 'THE IMPACT OF TRAINING AND CONFLICT AVOIDANCE ON RESPONSES TO SEXUAL HARASSMENT'P Pychology of Women Quarterly, 31, 62-72

Gray, A., Edgecliffe-Johnson, A., (2020) 'McDonald's flips position with attack on ex-chief' Financial Times (Europe) 6

Gruber, J.E., (1998) 'The impact of male work environments and organizational policies on women's experiences of sexual harassment' Gender \& Society, 12(3), 301-320

Gurchiek, K., (2018) ‘EEOC Drops Hammer on Workplace Harassment' SHRM [online] Available at https://www.shrm.org/resourcesandtools/hr-topics/employee-relations/pages/eeoc-dropshammer-on-workplace-harassment.aspx (Accessed 19 April 2021)

Hall, A., Asgari, N., Waters, R., (2019) 'Corporate liaisons have become dangerous' Financial Times (Europe) 15

Hill, A., (2011) 'Anita Hill: The Stories I Carry With Me' TIME [online] Available at https://ideas.time.com/2011/10/12/anita-hill-the-stories-i-carry-with-me/ (Accessed 23 March 2021)

Holland, K.J., Cortina, L.M., (2013) 'When Sexism and Feminism Collide: The Sexual Harassment of Feminist Working Women' Psychology of Women Quarterly 37(2) 192-208

Houle, J.N., Staff, J., Mortimer, J.T., Uggen, C., Blackstone, A., (2011) 'The Impact of Sexual Harassment on Depressive Symptoms during the Early Occupational Career' Society and Mental Health 1(2) 89-105

Hunt, C.M., Davidson, M.J., Fielden S.L., Hoel, H., (2010) 'Reviewing sexual harassment in the workplace - an intervention model' Personnel Review 39(5) 655-673

Isidore, C., (2005) 'Boeing CEO out in sex scandal' CNN Money [online] Available at https://money.cnn.com/2005/03/07/news/fortune500/boeing_ceo/ (Accessed 19 April 2021)

Jones, D., (2010) 'Was Boeing's punishment too harsh?' USA TODAY [online] Available at https://gallo.law/press/boeing_usatoday-030905.pdf (Accessed 19 April 2021)

Kindelan, K., (2019) 'Christine Blasey Ford reveals who inspired her to testify about Kavanaugh' abc NEWS Available at https://abcnews.go.com/GMA/News/christine-blasey-ford-revealsinspired-testify-kavanaugh/story?id=66660781 (Accessed 14 April 2021)

LeMaire, K.L., Oswald, D.L., Russell, B.L. (2016) 'Labeling Sexual Victimization Experiences: The Role of Sexism, Rape Myth Acceptance, and Tolerance for Sexual Harassment' Violence and Victims 31(2), 332-346 
Leskinen, E.A., Cortina, L.M., (2011) 'Gender Harassment: Broadening Our Understanding of Sex-Based Harassment at Work' Law Hum Behav 35 25-39

Lim, S., Cortina, L.M. (2005) 'Interpersonal Mistreatment in the Workplace: The Interface and Impact of General Incivility and Sexual Harassment' Journal of Applied Psychology 90(3), 483496

Magnusson Hanson, L.L., Nyberg, A., Mittendorfer-Rutz, A., Bondestam, F., Madsen, I.E.H., (2020) 'Work related sexual harassment and risk of suicide and suicide attempts: prospective cohort study' BMJ 2020;370:m2984. doi:10.1136/bmj.m2984

McDonald, P., Charlesworth, S., Graham, T., (2015) 'Developing a framework of effective prevention and response strategies in workplace sexual harassment' Asia Pacific Journal of Human Resources 53, 41-58

McDonald, P., (2012) 'Workplace Sexual Harassment 30 Years on: A Review of the Literature' International Journal of Management Reviews 14, 1-17

McLaughlin, H., Uggen, C., Blackstone, A. (2012) 'Sexual Harassment, Workplace Authority, and the Paradox of Power' American Sociological Review 77(4), 625-647

McLaughlin, H., Uggen, C., Blackstone, A. (2017) 'THE ECONOMIC AND CAREER EFFECTS OF SEXUAL HARASSMENT ON WORKING WOMEN' $\mathrm{NCBI}$ [online] Available at https://www.ncbi.nlm.nih.gov/pmc/articles/PMC5644356/ (Accessed 21 January 2021)

me too. [online] Available at https://metoomvmt.org/get-to-know-us/history-inception/ (Accessed 23 January 2021)

Merle, R., (2005) 'Boeing CEO Resigns Over Affair With Subordinate' The Washington Post [online] Available at https://www.washingtonpost.com/archive/politics/2005/03/08/boeing-ceoresigns-over-affair-with-subordinate/199b6a6b-9883-457d-991b-ea23840b1fe2/ (Accessed 19 April 2021)

Moore, T., (n.d.) 'THE TUMULTUOUS MARRIAGE BEHIND THE MCDONALD'S EMPIRE' Mel Magazine [online] Available at https://melmagazine.com/en-us/story/the-tumultuous-marriagebehind-the-mcdonalds-empire (Accessed 19 April 2021)

Napoli, L., (2016) 'Meet the Woman Who Gave Away the McDonald's Founder's Fortune' TIME [online] Available at https://time.com/4616956/mcdonalds-founder-ray-kroc-joan-kroc/ (Accessed 19 April 2021)

O'Donohue, W., Downs, K., Yeater, E.A. (1998) 'Sexual harassment: A review of the literature' Aggression and Violent Behaviour 3(2), 111-128

O'Hare, E.A., O'Donohue, W., (1998) 'Sexual Harassment: Identifying Risk Factors' Archives of Sexual Behaviour 27(6), 561-580

Pennebaker J.W., O'Heeron, R.C., (1984) 'Confiding in Others and Illness Rate Among Spouses of Suicide and Accidental-Death Victims' Journal of abnormal Psychology 93(4), 473-476 
Perez, P., (2019) 'The Drama-Free Workplace’ Hoboken, NJ: Wiley.

Roehling, M.V., Huang, J., (2018) 'Sexual harassment training effectiveness: An interdisciplinary review and call for research' Journal of Organizational Behavior 39, 134-150

Rospenda, K.M., Richman, J.A., Nawyn, S.J., (1998) 'DOING POWER The Confluence of Gender, Race, adn Class in Contrapower Sexual Harassment' Gender \& Society 12(40) 40-60

Stockdale, M.S., Bell, M.P., Crosby, F., Berdahl, J., (2020) 'From me too to what now: advancing scholarship on sex harassment issue 1: a persistent problem' Equality, Diversity and Inclusion: An International Journal 39(1), 1-4

Sweetland Edwards, H., (2018) 'How Christine Blasey Ford's Testimony Changed America' TIME [online] Available at https://time.com/5415027/christine-blasey-ford-testimony/ (Accessed 26 March 2021)

The Seattle Times (2016) 'Ex-Boeing CEO Stonecipher, wife, sue to keep dozen cats in 6,700square-foot N.C. house' The Seattle Times ed. 2017 [online] Available at https://www.seattletimes.com/nation-world/ex-boeing-ceo-stonecipher-wife-sue-to-keep-dozencats-in-6700-square-foot-nc-house/ (Accessed 19 April 2021)

UN Women (n.d.) 'What is Sexual Harassment' [online] Available at https://www.un.org/womenwatch/osagi/pdf/whatissh.pdf (Accessed 10 March 2021)

U.S. Equal Employment Opportunity Commission, (n.d.) 'Facts About Sexual Harassment' U.S. Equal Employment Opportunity Commission ed. 2002 [online] Available at https://www.eeoc.gov/fact-sheet/facts-about-sexual-harassment (Accessed 26 April 2021)

U.S. Equal Employment Opportunity Commission, (2010) 'Boeing Settles Two EEOC Sex Discrimination and Retaliation Lawsuits for $\$ 380,000$ ' U.S. Equal Employment Opportunity Commission [online] Available at https://www.eeoc.gov/newsroom/boeing-settles-two-eeoc-sexdiscrimination-and-retaliation-lawsuits-380000 (Accessed 19 April 2021)

U.S. Equal Employment Opportunity Commission, (2014) 'Wal-Mart to Pay $\$ 363,419$ to Settle EEOC Sexual Harassment and Retaliation Suit' U.S. Equal Employment Opportunity Commission [online] Available at https://www.eeoc.gov/newsroom/wal-mart-pay-363419-settle-eeoc-sexualharassment-and-retaliation-suit (Accessed 28 April 2021)

Williams, C.L., Giuffre, P.A., Dellinger, K., (1999) 'SEXUALITY IN THE WORKPLACE: Organizational Control, Sexual Harassment, and the Pursuit of Pleasure' Annual Review of Sociology 25, 73-93

Willness, C.R., Steel, P., Lee, K., (2007) 'A META-ANALYSIS OF THE ANTECEDENTS AND CONSEQUENCES OF WORKPLACE SEXUAL HARASSMENT' Personnel Psychology 60, 127162

Winer, Burritt, Tillis LLP(n.d.) 'Male Sexual Harassment in the Workplace' [online] Available at https://www.wmlawyers.com/oakland-sexual-harassment-attorneys/male/ (Accessed 5 February 2021)

Zeiger-Hill, V., Besser, A., Morag, J., Campbell, W.K., (2016) 'The Dark Triad and sexual harassment proclivity' Personality and Individual Differences 89, 47-54 